\title{
Decision-making autonomy of women and other factors of anemia among married women in Ethiopia: a multilevel analysis of a countrywide survey
}

Fentanesh Nibret Tiruneh* (D), Degnet Teferi Asres, Mesfin Wogayehu Tenagashaw and Hirut Assaye

\begin{abstract}
Background: Anemia is one of the world's public health problem, especially in developing nations. The majority of women of childbearing age (15-49) are affected by anemia. Women's role in the decision-making process is significant for their health and related issues such as anemia. So far, there is no evidence of women's decisionmaking autonomy on anemia. Consequently, this study aimed to robustly examine both individual- and group-level women's decision-making autonomy and other determinants of anemia among married women in Ethiopia.

Methods: We examined data from an Ethiopian demographic and health survey conducted in 2016. Our analysis included 9220 married women of childbearing age (15-49 years). For bivariate analysis, we applied the chi-squared $\left(X^{2}\right)$ test. The relationship between individual and group-level women's decision-making autonomy and anemia was assessed using multilevel binary logistic regression models while adjusting other socio-demographic and economic characteristics.

Results: In this study the magnitude of anemia was 30.5\% (95\% Cl; 29.5-31.4). According to our multilevel analysis, group-level women's autonomy was found to be negatively related with anemia than individual-level women's autonomy ( $\mathrm{AOR}=0.53,95 \% \mathrm{Cl}=0.41-0.69$ ). In addition, the indicator of women's wealth index at group level was a protective factor $(\mathrm{AOR}=0.68,95 \% \mathrm{Cl}=0.51-0.90)$ to develop anemia. Among individual-level indicators women's age $(A O R=0.73,95 \% \mathrm{Cl}=0.60-0.89)$, use of contraceptive $(A O R=0.66,95 \% \mathrm{Cl}=0.55-0.81)$, $\mathrm{BMI}(\mathrm{AOR}=0.71,95 \%$ $\mathrm{Cl}=0.59-0.86)$ and employment status ( $\mathrm{AOR}=0.88,95 \% \mathrm{Cl}=0.79-0.98)$ were negatively related with anemia. While women who follow Muslim religion ( $\mathrm{AOR}=1.62,95 \% \mathrm{Cl}=1.32-1.97$, ), women who had five and above number of children ( $A O R=93,95 \% \mathrm{Cl}=1.53-2.46)$, and who were pregnant $(A O R=1.21,95 \% \mathrm{Cl}=1.04-1.40)$ were positively associated with anemia.

Our final model showed that around $27 \%$ of the variability of having anemia was because of group-level differences (ICC $=0.27, P<0.001$ ). In addition, both individual and group-level factors account for $56.4 \%$ of the variance in the in the severity of anemia across communities (PCV $=56.4 \%)$.
\end{abstract}

\footnotetext{
* Correspondence: fantshnibret@gmail.com

Department of Applied Human Nutrition, Faculty of Chemical and Food Engineering, Bahir Dar Institute of Technology, Bahir Dar University, Bahir Dar, Ethiopia
}

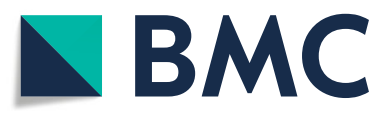

(c) The Author(s). 2021 Open Access This article is licensed under a Creative Commons Attribution 4.0 International License, which permits use, sharing, adaptation, distribution and reproduction in any medium or format, as long as you give appropriate credit to the original author(s) and the source, provide a link to the Creative Commons licence, and indicate if changes were made. The images or other third party material in this article are included in the article's Creative Commons licence, unless indicated otherwise in a credit line to the material. If material is not included in the article's Creative Commons licence and your intended use is not permitted by statutory regulation or exceeds the permitted use, you will need to obtain permission directly from the copyright holder. To view a copy of this licence, visit http://creativecommons.org/licenses/by/4.0/ The Creative Commons Public Domain Dedication waiver (http://creativecommons.org/publicdomain/zero/1.0/) applies to the data made available in this article, unless otherwise stated in a credit line to the data. 
Conclusions: Our study showed that empowering women within households is not only an important mechanism to reduce anemia among married women but also serves as a way to improve the lives of other women within the society.

Keywords: Anemia, Women's autonomy, Group-level, Individual-level, Ethiopia

\section{Background}

Anemia occurs when the number of red blood cells of the body is insufficient to meet the body's physiological needs. This is achieved by a hemoglobin concentration of less than $110 \mathrm{~g} / \mathrm{L}$ for pregnant women and $120 \mathrm{~g} / \mathrm{L}$ for non-pregnant women [1]. Globally about $29.4 \%$ of women of childbearing age and $38.2 \%$ of pregnant women are anemic. The problem is most common in developing nations which accounts for more than $89 \%$ $[2,3]$.

In Africa, more than $32.8 \%$ of women of childbearing age are anemic and in some African countries, the prevalence is far above 50\% [3, 4]. Although anemia control is a priority public health agenda in Ethiopia, 24\% of women of childbearing age group are anemic [5].

Numerous studies have envisaged lots of potential determinants of anemia among women particularly, repeated to births, residence, pregnancy status, nutritional status, age, and breastfeeding status [6-9]. However, there is the literature gap in the relationship between women's decision-making autonomy and the magnitude of anemia among them.

Autonomy is a multifaceted concept that encompasses certain powers to manage the personal environment by controlling resources and information, including freedom of movement, making decisions about one's personal concerns, or by close family members $[10,11]$. Women's autonomy is important in their own right and is crucially linked to women's health and health-related issue [12]. Evidence suggests that increasing the access of economic resources alone is insufficient but requires increased women's decision-making and control of household resources is also highly required. In order to practice good health-seeking behaviors, women's ability to participate in decision-making over certain important matters (such as major household purchases or personal health care) is essential $[13,14]$.

Policymakers and researchers have called for an emphasis on improving women's decision-making power to improve women's health and healthseeking behaviors in developing countries [15]. Studies in South Asia and sub-Saharan African countries indicated that women's decision-making autonomy has been linked to many positive outcomes such as reductions in infant mortality, better child and women nutritional outcomes, and increased use of health care services [16, 17].
Some studies indicated that the decision-making capabilities of women in a society might have also an effect on their health and health-related behavior, more than the effect of individual women's autonomy for two major reasons [18]. The first reason is that the presence of high numbers of a greater proportion of empowered women in a community could contribute to the information distribution related to better health outcomes to those with lower autonomous levels through formal and informal social networks [19]. The other reason is that communities with a higher proportion of autonomous women might be economically advantaged because more women are employed (working outside of the home). This will empower them to make better investments in the health sector creating an opportunity for less autonomous women more access to health information and services for themselves and their families [20].

In Ethiopia, although several pocket studies have examined the determinants of anemia, they largely focused only on individual-level characteristics and did not examine community determinants. To our knowledge, none have accounted for both individual and group-level women's autonomy related to anemia. Moreover, information that used a national representative sample and factors at the group-level that may have an effect on anemia among married women is typically overlooked.

Therefore, this study aimed to more robustly examine individual- and group-level women's decision-making autonomy and other factors of anemia amongst married women in Ethiopia. Being based on data from a nationally representative sample, this study will give imminent information for concerned stakeholders and policymakers to understand the determinants of anemia in order to design and implement feasible interventions both at individual and group levels. We hypothesized that women with a high level of decisionmaking autonomy at both the individual and group-levels are less likely to develop anemia than were their counterparts.

\section{Methods \\ Study sample}

Data obtained from the 2016 Ethiopia Demographic and Health Surveys (EDHS) was used for this study. The 2016 EDHS is a nationally representative database compiled by the National Central Statistical Agency (CSA). It is intended to generate representative assessments for the majority of national demographic and health indicators [5]. 
Households were chosen by using stratified twostage cluster sampling. In the first phase, a total of 645 clusters/enumeration areas (EAs) (202 in urban areas and 443 in rural areas) from a list of 84,915 EAs created for the 2007 Ethiopian Population and Housing Census (PHC) were randomly selected. In the second phase, 28 households were randomly selected for each cluster. In the 2016 EDHS, a cluster was defined as a census enumeration area covering 181 households on average. Of the 15,683 women interviewed, 5859 women were excluded because they were single. Among 9824 married women who selected for hemoglobin measurement, 604 women refused to participate in hemoglobin measurement. As a result, this study concentrated on 9220 married women of childbearing age (15-49 years) in 645 clusters who were tested for their hemoglobin level (Fig. 1).
Furthermore, face-to-face structured interviews were conducted. Before the survey, a pretest was conducted to ensure that the questions were clear for the study participants.

\section{Measures}

Outcome variable Anemia among married women is the outcome variable, measured as a categorical variable through predefined cut-off points for mild (110-119 g/dl for non-pregnant women, $100-109 \mathrm{~g} / \mathrm{dl}$ for pregnant women), moderate (80-109 for non-pregnant women, $70-99 \mathrm{~g} / \mathrm{dl}$ for pregnant women), and severe anemia (lower than $80 \mathrm{~g} / \mathrm{dl}$ for non-pregnant women, lower than 70 for pregnant women) as recommended by WHO [21]. However, due to the small number of cases in our dataset that fall into the categories of severe and mild

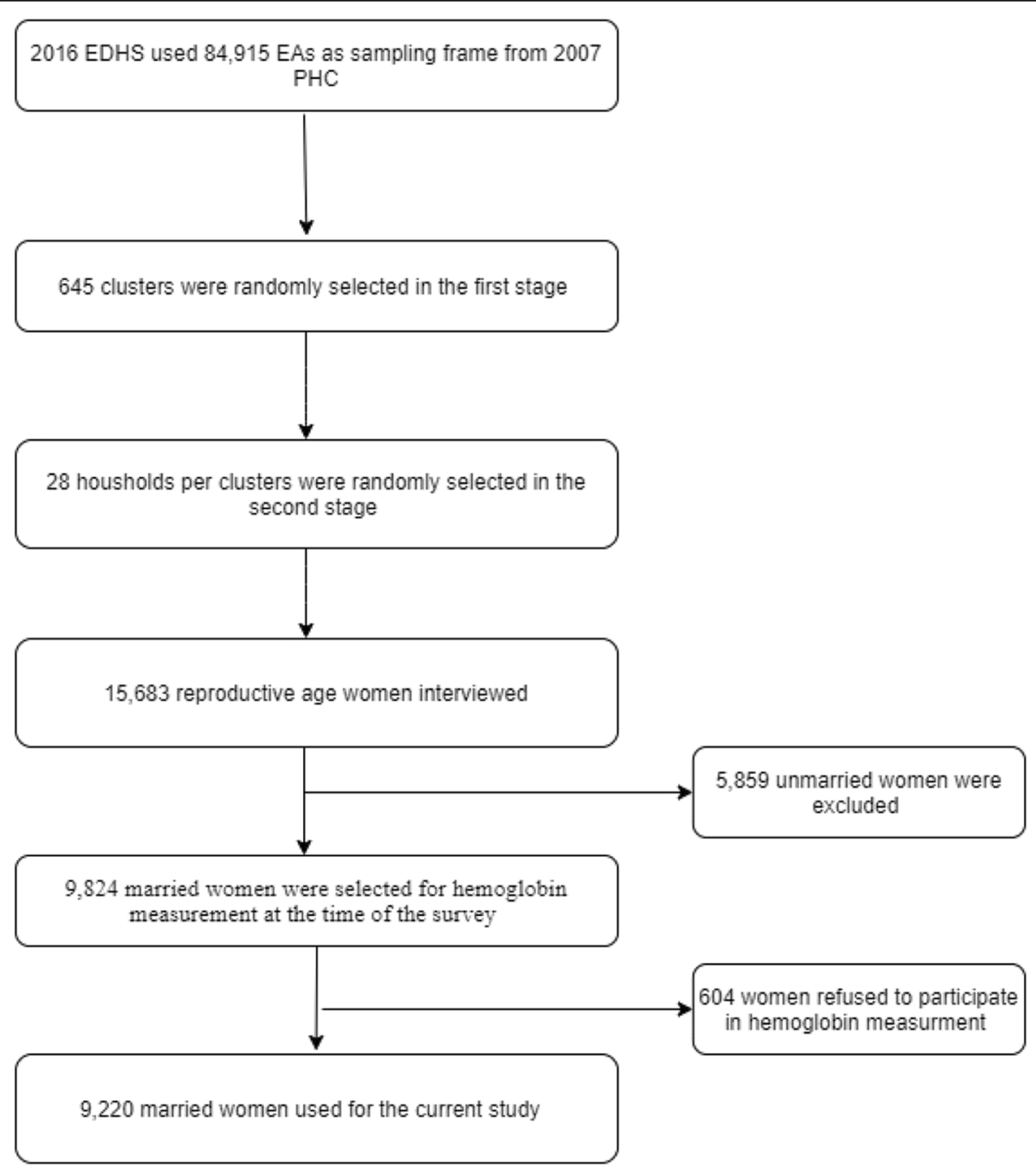

Fig. 1 Sampling procedure; from 2016 Ethiopian Demographic and Health Survey (EDHS) 
anemia, we recoded anemia levels as "0" for non-anemic and "1" for anemic [22].

Individual-level independent variables We selected the individual-level variables from the existing literatures $(10,12,16$, and 19).

Five key questions were used to assess women's decisionmaking autonomy. (a) Who makes health-care decisions for women? (Personal decision-making autonomy), (b) who makes decision on large household purchases (economic decision-making autonomy), (c) who decides on visits to friends or family (mobility decision-making autonomy), (d) who makes the decision about what to do with the husband's earnings and (e) who decides to use contraception. Following these questions, women, who made all of the above decisions, either alone or with her husband, were classified as having high decision-making autonomy, whereas the other women were classified as having low decision-making autonomy [23].

Other individual-level variables included in our study were respondents' age (15-24,

$25-34$, and 35-49 years); age of first marriage $(<16$, 16-20 and $>20$ ), religion (Orthodox, protestant Muslim and others), level of education (no education, primary, secondary and higher), employment status (no/yes), education level of husband (no education, primary, secondary and higher), place of residence (urban/rural), number of children ever born (0,1-2,3-4 and +5), current pregnancy (no/yes), currently breastfeeding (no/ yes), amenorrheic (no/yes) at the time of data collection, women's BMI (underweight, normal weight and overweight), history of terminated pregnancy (no/yes), health insurance coverage (no/yes), whether women chewed chat (no/yes) and health service utilization within 1 year (no/yes). The wealth index was an integrated measure of household properties such as televisions, bicycles, building materials, access to water, sanitation facilities and other wealth-related aspects. Factor scores of household assets were developed using principal component analysis. The lowest $45.5 \%$ of the scores were classified as poor, while the remaining scores were classified as nonpoor [24].

Community-level independent variables A community (cluster) is defined as a census enumeration area covering 181 households on average [5]. In this study, we included five group-level variables. One variable indicates an area of residence, (place of residence). Four grouplevel variables were obtained by combining individual responses for each item to the group level. These were the percentage of women with a high level of decisionmaking autonomy, attained higher education, had a nonpoor wealth index and had ever chewed chat in the community. On the basis of tertiles, each combined variable was classified as low, medium, or high. The selected community-level variables represented the norms and social contexts of the community regarding women's decision-making autonomy, the availability of health related resources, and the socioeconomic status of the community [25].

\section{Statistical examinations}

All statistical examinations were done using SAS 9.4. Distribution of the respondent's individual and grouplevel characteristics with anemia was assessed using Chisquare tests. Those explanatory variables that showed significance $(p<0.25)$ in the $\mathrm{x}^{2}$-square analysis were included for multivariate analysis. Multilevel binary logistic regression models were constructed by using the "GLIMMIX" command in SAS to simultaneously analyze the relationships of the individual- and group-level factors with anemia.

\section{Modeling approaches}

Three modeling methods were used: fixed effects, random effects, and goodness of fit.

\section{Fixed effect}

The multilevel binary logistic regression model's fixed effects were reported as adjusted odds ratios (AORs) with $95 \%$ confidence intervals (CI).

\section{Random effect}

Community variance in each model was assessed by using the intraclass correlation coefficient (ICC) and proportional change in variance $(\mathrm{PCV})$.

$$
\mathrm{ICC}=\frac{\operatorname{var}(b)}{\operatorname{var}(b)+\operatorname{var}(w)},
$$

Where $\operatorname{Var}(\mathrm{b})$ is the group level variance. $\operatorname{Var}(\mathrm{w})$ is the standard logistic distribution, which is the assumed individual variance component, which is $\frac{\pi^{2}}{3} \approx 3.29$ [26].

$$
\mathrm{PCV}=\frac{\text { Est } 0-\text { Estimate for } \operatorname{model}\left({ }^{\wedge}\right)}{\text { Est } 0} * 100 .
$$

Where Est0 is an estimate from null model and $\left({ }^{\wedge}\right)$ is an Estimate from model 1, 2, and 3.

There were four models produced. For entering variables into the multivariate models, we used a hierarchical approach. The initial model (null model) comprised only the outcome variable to examine the variation in anemia across communities/groups. The second model (model with only individual-level variables), the third model (model with only group-level variables) and the final multilevel model include both individual level and group level variables that are fitted with anemia at the same time. 


\section{Goodness of fit}

Each model's goodness-of-fit was evaluated by using the Bayesian Information Criteria (BIC), a lower value indicates that the model is better fit. To assess multicollinearity, the variance inflation factor (VIF) and tolerance were used. None of the variables showed signs of multicollinearity (all VIF $<10$ and all tolerance $>0.1$ ) (See supplementary Table 1).

\section{Ethical considerations}

The survey protocol, which included biomarker collection, was reviewed and approved by the Ministry of Innovation and Technology, the Federal Democratic Republic of Ethiopia, and the ICF International Institutional Review Board. At the start of data collection, participants provided informed consent, and the authors sought permission from the DHS program to use the data: https://dhsprogram.com/data/dataset/Ethiopia Standard-DHS_2016.cfm?flag=0

\section{Results}

The magnitude of anemia among married women in our study was $30.5 \%$ (95\% CI: $29.5-34.4$ ). About $39 \%$ of respondents had high decision-making autonomy at household level (Table 1). Table 1 also shows information about the sampled women's socioeconomic and demographic characteristics. The majorities of women were from rural areas, had no formal education, and were unemployed. Regarding household wealth status, 45.5 and $54.5 \%$ of study respondents were from poor and non-poor households,' respectively. Approximately $65 \%$ of the married women had normal nutritional status $(\mathrm{BMI}=18.5-24.9)$. Furthermore, only $4.1 \%$ of participants had health insurance.

The findingss of the bivariate analysis of both individual- and group-level factors and anemia prevalence were presented in (Table 2). Women's decision making autonomy at household, age, age at first marriage, religion, educational level, educational level of husband, employment status, pregnancy and breastfeeding status, number of children ever born, contraceptive use, wealth index, nutritional status, insurance coverage and whether women visit the health facility in the last 12 months were individual level factors that showed statistically significance difference with anemia. Place of residence, community-level women's decision-making power, education, wealth index, were also showed significantly associated with anemia among community-level factors.

Table 3 displays the findings from the multilevel analyses. The findings of the empty model (model1), which only included the outcome variable, confirmed a significant variance in the magnitude of anemia among women across communities. Group level factors accounted for
$46 \%$ of the total variance in anemia prevalence $($ ICC $=$ $0.46, p<0.001)$.

Model 2 which included outcome and only individuallevel variable, showed that women's age, region, place of residence, employment status, pregnancy status, use of contraception, household wealth index and BMI were significantly related to anemia; the ICC revealed that $29 \%$ of the difference in the prevalence of anemia among married women was because of the variation at the group level factors (ICC $=0.29, p<0.001)$. According to $\mathrm{PCV}$, individual level factors account for $50.7 \%$ variation in the odds of having anemia across communities.

The analysis of the outcome and only group-level variables presented in model 3 indicated that group-level women's decision-making autonomy and wealth index were significantly associated with anemia. The result confirmed that $39 \%$ of the variation of anemia was due to the community differences ( $\mathrm{ICC}=0.39, p<0.001$ ). Community- level factors account for $23.2 \%$ of the variation in the odds of having anemia across communities $(\mathrm{PCV}=23.2 \%)$.

In the final model (model 4), including the outcome variable and both the individual and group-level characteristics at the same time, showed that the risk of anemia was $27 \%(\mathrm{AOR}=0.73 ; 95 \% \mathrm{CI}=0.60-0.89)$ lower among older women than younger women. Women who follow Muslim religions had 1.62 times higher risk of having anemia $(\mathrm{AOR}=1.62,95 \% \mathrm{CI}=1.32-1.97)$ than women who follow orthodox religion. When compared to unemployed women, employed women had a $12 \%$ lower risk of anemia $(\mathrm{AOR}=0.88,95 \% \mathrm{CI}=0.79-0.98)$. Women who became pregnant during the data collection period were 1.21 times $(\mathrm{AOR}=1.21,95 \% \mathrm{CI}=1.04$ 1.40) more likely to have anemia than their counterparts. Women who had more than five children had 1.93 $(\mathrm{AOR}=1.93,95 \% \mathrm{CI} 1.53-2.46)$ times the odds of having anemia as compared to women who did not have a child. Women who used contraceptive methods at the time of data collection had a $34 \%(\mathrm{AOR}=0.66 ; 95 \% \mathrm{CI}=$ 0.55-0.81) lower risk of anemia. Regarding nutritional status of women, Anemia was found to be 0.71 times less likely in overweight women than in underweight women (AOR $=0.71,95 \% \mathrm{CI}=0.59-0.86$ ).

Among group-level factors, women's decision-making power and wealth index were statistically related with anemia. The chance of having anemia were $50 \%(\mathrm{AOR}=$ $0.50,95 \% \mathrm{CI}=0.47-0.69)$ and $22 \%(\mathrm{AOR}=0.78,95 \%$ $\mathrm{CI}=0.52-0.98)$ lower among women in a group with agreater percentage of women who had high decisionmaking power and non-poor wealth index, respectively than their counterparts. Even after the inclusion of both individual and group-level indicators, the difference of having anemia across communities continued significant; as demonstrated by the estimated ICC, $27 \%$ of the 
Table 1 Characteristics of sample married women in the Ethiopia 2016 Demographic and Health Survey (EDHS) sample

\begin{tabular}{|c|c|c|}
\hline & Frequency & $\%$ \\
\hline \multicolumn{3}{|c|}{ outcome variable (Anemia) } \\
\hline None anemic & 6412 & 69.5 \\
\hline Anemic & 2808 & 30.5 \\
\hline \multicolumn{3}{|c|}{ Individual-level Characteristics $(n=9220)$} \\
\hline \multicolumn{3}{|l|}{ Women's autonomy } \\
\hline Low & 7196 & 61.0 \\
\hline High & 3597 & 39.0 \\
\hline \multicolumn{3}{|c|}{ Socio demographic and economic characteristics } \\
\hline \multicolumn{3}{|l|}{ Women's Age } \\
\hline $15-24$ & 2294 & 24.9 \\
\hline $25-34$ & 3852 & 41.9 \\
\hline $35-49$ & 3074 & 33.3 \\
\hline \multicolumn{3}{|c|}{ Women's age at first Marriage } \\
\hline$<16$ & 3519 & 38.2 \\
\hline $16-20$ & 4194 & 45.5 \\
\hline$>20$ & 1507 & 16.3 \\
\hline \multicolumn{3}{|l|}{ Religion } \\
\hline Orthodox & 3337 & 36.2 \\
\hline Protestant & 1706 & 18.5 \\
\hline Muslim & 3998 & 43.4 \\
\hline Others & 179 & 1.9 \\
\hline \multicolumn{3}{|c|}{ Women's education level } \\
\hline No Education & 5387 & 58.4 \\
\hline Primary & 2553 & 27.7 \\
\hline Secondary & 805 & 8.7 \\
\hline Higher & 475 & 5.1 \\
\hline \multicolumn{3}{|c|}{ Education level of husband or partner } \\
\hline No education & 4192 & 45.5 \\
\hline Primary & 2905 & 31.5 \\
\hline Secondary & 1126 & 12.2 \\
\hline Higher & 911 & 9.9 \\
\hline \multicolumn{3}{|c|}{ Women's employment } \\
\hline No & 6267 & 67.9 \\
\hline Yes & 2953 & 23.1 \\
\hline \multicolumn{3}{|l|}{ Currently pregnant } \\
\hline No & 8199 & 88.3 \\
\hline Yes & 1021 & 11.1 \\
\hline \multicolumn{3}{|c|}{ Currently breastfeeding } \\
\hline No & 5379 & 58.3 \\
\hline Yes & 3841 & 41.7 \\
\hline \multicolumn{3}{|c|}{ Currently amenorrheic } \\
\hline No & 6753 & 73.2 \\
\hline Yes & 2467 & 26.8 \\
\hline
\end{tabular}

Number of children ever born 
Table 1 Characteristics of sample married women in the Ethiopia 2016 Demographic and Health Survey (EDHS) sample (Continued)

\begin{tabular}{|c|c|c|}
\hline & Frequency & $\%$ \\
\hline 0 & 889 & 9.6 \\
\hline $1-2$ & 2749 & 29.8 \\
\hline $3-4$ & 2205 & 23.9 \\
\hline $5+$ & 337 & 36.6 \\
\hline \multicolumn{3}{|l|}{ Current use of contraceptive } \\
\hline No & 6402 & 69.4 \\
\hline Yes & 2818 & 30.6 \\
\hline \multicolumn{3}{|l|}{ Women ever chewed Chat } \\
\hline No & 8174 & 88.7 \\
\hline Yes & 1046 & 11.3 \\
\hline \multicolumn{3}{|l|}{ Wealth Index } \\
\hline Poor & 4198 & 45.5 \\
\hline Non-Poor & 5022 & 54.5 \\
\hline \multicolumn{3}{|c|}{ History of terminated pregnancy } \\
\hline No & 8233 & 89.3 \\
\hline Yes & 987 & 10.7 \\
\hline \multicolumn{3}{|l|}{ Women's BMI } \\
\hline < 18.5(underweight) & 2078 & 22.5 \\
\hline 18.5-24.9(normal weight) & 6010 & 65.2 \\
\hline$\geq 25$ (overweight) & 1132 & 12.3 \\
\hline \multicolumn{3}{|l|}{ Health care access } \\
\hline \multicolumn{3}{|l|}{ Covered by health insurance } \\
\hline No & 8841 & 95.9 \\
\hline Yes & 379 & 4.1 \\
\hline \multicolumn{3}{|c|}{ Visiting health facility in the last 12 months } \\
\hline No & 4558 & 49.4 \\
\hline Yes & 4662 & 50.6 \\
\hline
\end{tabular}

Community-level characteristics

Place of residence

Urban

Rural

$\%$ of women with high decision-making autonomy

Low

$\%$ of women with non-poor wealth index

Low

Medium

High

$\%$ women with higher education

Low

Medium 
Table 1 Characteristics of sample married women in the Ethiopia 2016 Demographic and Health Survey (EDHS) sample (Continued)

\begin{tabular}{lcc}
\hline & Frequency & $\%$ \\
\hline \% women who chewed chat & 315 & 48.8 \\
Low & \multicolumn{1}{c}{173} & 26.8 \\
Medium & 157 & 24.3 \\
\hline
\end{tabular}

variation of having anemia was due to community differences $(\mathrm{ICC}=0.27, P<0.001$ ). Furthermore, according to the PCV, $56.4 \%$ of the difference in the likelihood of having anemia across communities is described by both individual and community-level determinants (Table 3).

\section{Discussion}

Our findings revealed that the magnitude of anemia among married women in Ethiopia was relatively high $30.5 \%$ (95\% CI $=29.5-31.4$ ) compared to those reported in the nationwide study among lactating and reproductive age of women $[5,22]$. This indicates that married women are at a greater risk of anemia. The majority of respondents (61\%) in our sample had low decisionmaking autonomy at home. Therefore, the greater magnitude of anemia in our sample could be due to the low decision-making capacity of women to access resources and health information. Gender power dynamics influence how and who makes health-related decisions [27].) In families and communities, this power dynamics can affect health-seeking processes such as healthy eating patterns and health outcomes. Globally and especially in sub-Saharan African countries such as Ethiopia, men frequently make decisions regarding their wives' health $[28,29]$.. Poor women's welfare is a barrier to reaching the eventual aim of universal health. This suggests that substantial work is required to decrease the magnitude of anemia among married females, as it has a negative impact on the well-being of mothers, children, and the rest of the family.

This study has determined that in comparing the impact of individual-level women's decision-making with anemia, the effect of group level decision making power was considered significant. Women living in a society with a high percentage of women with high decisionmaking status were less likely to develop anemia even after we controlled their decision-making status and other factors at the individual and group level. This may be because social interactions in Ethiopia are often intertwined and therefore, the effect of group group-level autonomy on individual behavior may exceed the individual's autonomy [30]. The group level may indicate that even though Ethiopian women have low decisionmaking power, living in a strong decision-making society for women can lead to increased use of shared information and resources and ultimately, help improve the quality of life for women and their family members as well [18]. Female decision-making power at the group level had a beneficial effect on lowering the risk of anemia, implying that gender disparity, as measured by low decision-making power, may influence the development of anemia among married women.

In addition to group-level women's autonomy, our analyses revealed that the group-level wealth index had a greater impact than the effects of the individual-level wealth index on anemia. A high group-level wealth index was related to reduce odds of having anemia. Prior studies also demonstrated the positive relationship between community economic status and women's health; economically poorer communities have deficient health information and services [31, 32]. Therefore, interventions aimed at empowering women economically at the group level should be considered to reduce the prevalence of anemia and other health-related problems.

Unlike the findings of other studies $[6,9,33,34]$, our study found that older women had a lower risk to develop anemia than younger ones. The possible reason for this finding is that during adolescence, pregnancy and lactation, younger women have increased iron requirements and to compensate for menstruation-related blood loss [35]. The high percentage of early married women in our sample may provide another possible explanation. Our study found that more than $83 \%$ of women were married before the age of 20 years and according to our bivariate analysis, the prevalence of anemia among them was also significantly higher $(10.8 \%$ vs. $5.0 \%)$. \%). In Ethiopia, child marriage is common, and decisions about having children and using birth control are often made by husbands $[36,37]$. Furthermore, the customs of Ethiopian society strongly oppose the postponement of the first child after marriage, leading to a higher rate of adolescent birth. Therefore, the greater magnitude of anemia among younger females might be because of adolescent pregnancy and childbirth. This implies interventions such as educating the parents and community members who eventually bear the majority of determinations about girls marriage; empowering girls with information (such as exposure to media) about the consequences of early marriage and pregnancy, improving the accessibility and standard of formal education 
Table 2 Bivariate analyses of individual and group-level factors with Anemia among married women in Ethiopia

\begin{tabular}{|c|c|c|c|}
\hline & \multicolumn{2}{|c|}{ Anemic } & \multirow{2}{*}{$\begin{array}{l}P \text { - } \\
\text { value }\end{array}$} \\
\hline & No\% & Yes\% & \\
\hline \multicolumn{4}{|l|}{ Individual-level Characteristics $(n=9220)$} \\
\hline \multicolumn{4}{|l|}{ Women's autonomy } \\
\hline Women's decision-making power at home & & & $<0.001$ \\
\hline Low & 50.8 & $24.7^{*}$ & \\
\hline High & 20.0 & 4.5 & \\
\hline \multicolumn{4}{|l|}{ Socio demographic and economic characteristics } \\
\hline \multicolumn{4}{|l|}{ Women's Age } \\
\hline $15-24$ & 16.9 & $6.8^{*}$ & 0.048 \\
\hline $25-34$ & 29.5 & 12.5 & \\
\hline $35-49$ & 24.4 & 9.9 & \\
\hline Women's age at first Marriage & & & $<0.001$ \\
\hline$<16$ & 25.0 & $10.8^{*}$ & \\
\hline $16-20$ & 31.3 & 13.4 & \\
\hline$>20$ & 14.5 & 5.0 & \\
\hline Religion & & & $<0.001$ \\
\hline Orthodox & 32.2 & $7.5^{*}$ & \\
\hline Protestant & 12.9 & 5.4 & \\
\hline Muslim & 24.4 & 15.9 & \\
\hline Others & 1.35 & 0.4 & \\
\hline Women's education level & & & $<0.001$ \\
\hline No Education & 32.2 & $16.8^{*}$ & \\
\hline Primary & 22.8 & 7.9 & \\
\hline Secondary & 9.8 & 3.0 & \\
\hline Higher & 6.0 & 1.4 & \\
\hline Education level of husband or partner & & & 0.003 \\
\hline No education & 27.64 & $15.2^{*}$ & \\
\hline Primary & 23.4 & 8.6 & \\
\hline Secondary & 10.0 & 3.6 & \\
\hline Higher & 8.5 & 2.4 & \\
\hline Women's employment & & & $<0.001$ \\
\hline No & 44.0 & $20.7^{*}$ & \\
\hline Yes & 26.9 & 8.5 & \\
\hline Currently pregnant & & & $<0.001$ \\
\hline No & 65.15 & $25.7^{*}$ & \\
\hline Yes & 5.7 & 3.4 & \\
\hline Currently breastfeeding & & & $<0.001$ \\
\hline No & 47.3 & $18.5^{*}$ & \\
\hline Yes & 23.5 & 10.7 & \\
\hline Currently amenorrheic & & & $<0.001$ \\
\hline No & 56.5 & 22.0 & \\
\hline Yes & 14.3 & 7.2 & \\
\hline Number of children ever born & & & $<0.001$ \\
\hline 0 & 8.5 & $2.2^{*}$ & \\
\hline
\end{tabular}


Table 2 Bivariate analyses of individual and group-level factors with Anemia among married women in Ethiopia (Continued)

\begin{tabular}{|c|c|c|c|}
\hline & \multicolumn{2}{|c|}{ Anemic } & \multirow{2}{*}{$\begin{array}{l}P \text { - } \\
\text { value }\end{array}$} \\
\hline & No\% & Yes\% & \\
\hline $1-2$ & 24.5 & 8.3 & \\
\hline $3-4$ & 15.9 & 6.9 & \\
\hline $5+$ & 22.0 & 11.8 & \\
\hline Current use of contraceptive & & & $<0.001$ \\
\hline No & 43.55 & $22.8^{*}$ & \\
\hline Yes & 27.3 & 6.4 & \\
\hline Women ever chewed Chat & & & 0.064 \\
\hline No & 63.3 & 26.0 & \\
\hline Yes & 7.5 & 3.2 & \\
\hline Wealth Index & & & $<0.001$ \\
\hline Poor & 23.6 & $14.8^{*}$ & \\
\hline Non-Poor & 47.2 & 14.4 & \\
\hline History of terminated pregnancy & & & 0.039 \\
\hline No & 63.9 & 26.5 & \\
\hline Yes & 6.9 & 2.7 & \\
\hline Women's BMI & & & $<0.001$ \\
\hline$<18.5$ (underweight) & 13.01 & $7.4^{*}$ & \\
\hline 18.5-24.9(normal weight) & 46.5 & 18.0 & \\
\hline$\geq 25$ (overweight) & 11.3 & 3.8 & \\
\hline \multicolumn{4}{|l|}{ Health care access } \\
\hline Covered by health insurance & & & $<0.001$ \\
\hline No & 67.2 & $28.4^{*}$ & \\
\hline Yes & 3.6 & 0.8 & \\
\hline Visiting health facility in the last 12 & & & $<0.001$ \\
\hline No & 35.15 & $16.5^{*}$ & \\
\hline Yes & 35.7 & 12.7 & \\
\hline \multicolumn{4}{|l|}{ Community-level characteristics } \\
\hline \multicolumn{4}{|l|}{ Place of residence } \\
\hline Urban & 26.6 & $7.5^{*}$ & \\
\hline Rural & 44.2 & 21.7 & \\
\hline \multicolumn{4}{|c|}{$\%$ of women with high decision-making autonomy } \\
\hline Low & 17.5 & $14.3^{*}$ & $<0.001$ \\
\hline Medium & 18.2 & 6.2 & \\
\hline High & 35.1 & 8.7 & \\
\hline$\%$ women with higher education & & & $<0.001$ \\
\hline Low & 22.0 & $12.5^{*}$ & \\
\hline Medium & 30.3 & 9.9 & \\
\hline High & 18.5 & 6.7 & \\
\hline$\%$ of women with non-poor wealth index & & & $<0.001$ \\
\hline Low & 15.2 & $11.5^{*}$ & \\
\hline Medium & 20.9 & 7.9 & \\
\hline High & 34.8 & 9.8 & \\
\hline
\end{tabular}

$\%$ women who chewed chat 
Table 2 Bivariate analyses of individual and group-level factors with Anemia among married women in Ethiopia (Continued)

\begin{tabular}{clll}
\hline & Anemic & Yes\% & v- \\
\cline { 2 - 3 } & No\% & 19.9 \\
\hline Low & 47.6 & 9.3 \\
High & 23.2 & \\
\hline${ }^{*} P<0.05$ & &
\end{tabular}

for girls must be prioritized in order to preclude girls marriage and having children. Furthermore, all females of childbearing age need to take iron and folic acid supplements to avoid anemia [38].

In this study, we found that when compared to orthodox followers, Muslim and Protestant women were 37 and $62 \%$ more likely to develop anemia, respectively. The possible reason for this result may be due to different dietary patterns among different religious followers. In Ethiopian Orthodox Church, more than 200 days including every Wednesday and Friday in a year are dedicated to religious fasting, which includes abstaining from all types of animal-based foods [39]. Good plant sources of iron including legumes (beans, peas, and lentils), pumpkin, flaxseeds, and vegetables such as spinach, beets and chard are common foods in the fasting dishes. Moreover, Shiro wot, basically made from ground beans/chickpeas, and is also particularly popular as a fasting food among orthodox followers in Ethiopia and relatively inexpensive. Thus, women may get enough non-heme iron from plant-based foods. A longitudinal study conducted in Greek also reported that orthodox fasters had significantly higher iron intake at the end of the fasting period compared to non-fasters [40]. Another potential explanation for the greater magnitude of anemia amongst Muslim females, perhaps because of large family sizes [41-43]. An additional reason may be the frequent consumption of milk and milk product (attribute to iron absorption inhibitor) among Muslim women because most of them are living in the lowlands of the eastern part of Ethiopia (Afar and Somali regions) mostly live on pastoralism. Consumption of iron-rich cereals such as Teff (Eragrostis tef), which is common in the highlands of Ethiopia is also rare in these regions of the country [44]. However, further studies regarding the relationship between religion and anemia status in Ethiopia are worth doing.

Our findings supported the findings of other studies by demonstrating that female employment was negatively associated with anemia [22, 45, 46]. The lower prevalence of anemia among working women could indicate financial advantage as women who were employed can earn relatively a higher wage and purchase a wider range of foods including iron-rich ones [47]. Another reason could be that married women who are employed have better decision-making autonomy to receive health- related information and the ability to practice a healthy dietary pattern [22].

This study showed that pregnancy augmented the likelihood of anemia occurrence among married females. During pregnancy, the volume of bloodlines increases, consequently iron and vitamins are needed to make more red blood cells [48].. Greater fluid is produced to help fetal growth and development, however this is only feasible if the body can bulid the desired number of red blood cells; these physiological alterations rise the threat of anemia, particularly if the woman's nutritional desires are not met [49]. Pregnant ladies who are anemic have poor pregnancy consequences such as low birth weight and stillbirths, and can even result in the mother's death [50]. This suggests emphasizing proper nutrition and iron supplement for women, especially during pregnancy.

This study found that, women who have ever given birth have a higher risk of developing anemia than women who have never had a child. Moreover, the prevalence of anemia increased with an increased number of children. This might be related with a reduction of maternal iron reserves at every pregnancy and blood loss at each delivery. Another possible reason may be due to the fact that increasing family size could be linked with food insecurity. This finding is consistent with other previous study findings [51, 52].

Contraceptive use was found to be inversely related to anemia in our study. A possible explanation is that contraception use can have a significant impact on achieving good nutrition outcomes by assisting women in delaying pregnancy, spacing births, and reducing a woman's fertility. Well-spaced births allow women's bodies to recover and replenish essential nutrients such as iron, resulting in better nutritional outcomes [53]. The inverse relationship between contraceptive use and anemia has important implications for educating healthcare providers and women about the additional nutritional benefits of contraception use [54].

In this study, underweight women were more likely to suffer from anemia compared to overweight women. Studies conducted in Nepal, South Asia, Jordan, Japan and Rwanda [55-59], also reported similar findings. Women who are malnourished are a greater risk to be insufficient in crucial nutrients including iron, which may be linked with an expanded the threat of anemia 
Table 3 Multilevel analyses of factors associated with anemia, among married women in Ethiopia

\begin{tabular}{|c|c|c|c|c|}
\hline Variables & Model I & $\begin{array}{l}\text { Model } 2 \\
\text { AOR }(95 \% \mathrm{Cl})\end{array}$ & Model 3 AOR(95\%Cl) & Model 4 AOR( $95 \% C$ \\
\hline \multicolumn{5}{|c|}{ Individual -level characteristics $(n=9220)$} \\
\hline \multicolumn{5}{|l|}{ Women's autonomy } \\
\hline \multicolumn{5}{|c|}{ Women's decision-making power at home } \\
\hline Low & & 1.00 & & 1.00 \\
\hline High & & $0.95(0.72-1.17)$ & & $0.97(0.79-1.21)$ \\
\hline \multicolumn{5}{|c|}{ Socio demographic and economic characteristics } \\
\hline \multicolumn{5}{|l|}{ Women's Age } \\
\hline $15-24$ & & 1.00 & & 1.00 \\
\hline $25-34$ & & $0.867(0.74-1.01)$ & & $0.88(0.76-1.03)$ \\
\hline $35-49$ & & $0.71(0.58-0.86)^{*}$ & & $0.73(0.60-0.89)^{*}$ \\
\hline \multicolumn{5}{|c|}{ Women's age at first Marriage } \\
\hline$<16$ & & 1.00 & & 1.00 \\
\hline $16-20$ & & $1.06(0.95-1.18)$ & & $1.05(0.95-1.17)$ \\
\hline$>20$ & & $1.15(0.98-136)$ & & $1.14(0.97-1.34)$ \\
\hline \multicolumn{5}{|l|}{ Religion } \\
\hline Orthodox & & 1.00 & & 1.00 \\
\hline Protestant & & $1.44(1.17-1.77)^{*}$ & & $1.37(1.11-1.68)^{*}$ \\
\hline Muslim & & $1.92(1.60-2.31)^{*}$ & & $1.62(1.32-1.97)^{*}$ \\
\hline Others & & $1.12(0.74-1.69)$ & & $1.02(0.67-1.53)$ \\
\hline \multicolumn{5}{|c|}{ Women's education level } \\
\hline No Education & & 1.00 & & 1.00 \\
\hline Primary & & $0.89(0.79-1.01)$ & & $0.89(0.45-1.28)$ \\
\hline Secondary & & $1.03(0.84-1.27)$ & & $1.04(0.84-1.28)$ \\
\hline Higher & & $0.87(0.65-1.16)$ & & $0.87(0.65 .1 .16)$ \\
\hline \multicolumn{5}{|c|}{ Education level of husband or partner } \\
\hline No education & & 1.00 & & 1.00 \\
\hline Primary & & $0.95(0.83-1.06)$ & & $0.95(0.85-1.08)$ \\
\hline Secondary & & $1.10(0.92-1.32)$ & & $1.10(0.92-1.32)$ \\
\hline Higher & & $0.99(0.80-1.24)$ & & $0.99(0.79-1.24)$ \\
\hline \multicolumn{5}{|c|}{ Women's employment } \\
\hline No & & 1.00 & & 1.00 \\
\hline Yes & & $0.88(0.79-0.89)^{*}$ & & $0.88(0.79-0.98)^{*}$ \\
\hline \multicolumn{5}{|c|}{ Currently pregnant } \\
\hline No & & 1.00 & & 1.00 \\
\hline Yes & & $1.21(1.04-1.40)^{*}$ & & $1.21(1.04-1.40)^{*}$ \\
\hline \multicolumn{5}{|c|}{ Currently breastfeeding } \\
\hline No & & 1.00 & & 1.00 \\
\hline Yes & & $1.06(0.94-1.20)$ & & $1.06(0.94-1.20)$ \\
\hline \multicolumn{5}{|c|}{ Currently amenorrheic } \\
\hline No & & 1.00 & & 1.00 \\
\hline Yes & & $1.01(0.89-1.14)$ & & $1.01(0.88-1.14)$ \\
\hline \multicolumn{5}{|c|}{ Number of children ever born } \\
\hline 0 & & 1.00 & & 1.00 \\
\hline
\end{tabular}


Table 3 Multilevel analyses of factors associated with anemia, among married women in Ethiopia (Continued)

\begin{tabular}{|c|c|c|c|c|}
\hline Variables & Model I & $\begin{array}{l}\text { Model } 2 \\
\text { AOR(95\%Cl) }\end{array}$ & Model 3 AOR(95\%Cl) & Model 4 AOR(95\%Cl) \\
\hline $1-2$ & & $0.46(1.21-1.77)^{*}$ & & $1.45(1.20-1.75)^{*}$ \\
\hline $3-4$ & & $1.65(1.33-2.06)^{*}$ & & $1.63(1.31-2.03)^{*}$ \\
\hline $5+$ & & $2.01(1.57-2.53)^{*}$ & & $1.93(1.53-2.46)^{*}$ \\
\hline \multicolumn{5}{|c|}{ Current use of contraceptive } \\
\hline No & & 1.00 & & 1.00 \\
\hline Yes & & $0.64(0.53-0.78)^{*}$ & & $0.66(0.55-0.81)^{*}$ \\
\hline \multicolumn{5}{|c|}{ Women ever chewed Chat } \\
\hline No & & 1.00 & & 1.00 \\
\hline Yes & & $0.97(0.82-1.15)$ & & $0.98(0.83-1.17)$ \\
\hline \multicolumn{5}{|l|}{ Wealth Index } \\
\hline Poor & & 1.00 & & 1.00 \\
\hline Non-Poor & & $0.82(0.72-0.94)^{*}$ & & $0.91(0.79-1.04)$ \\
\hline \multicolumn{5}{|c|}{ History of terminated pregnancy } \\
\hline No & & 1.00 & & 1.00 \\
\hline Yes & & $0.93(0.80-1.08)$ & & $0.93(0.80-1.08)$ \\
\hline \multicolumn{5}{|l|}{ Women's BMI } \\
\hline$<18.5$ & & 1.00 & & 1.00 \\
\hline $18.5-24.9$ & & $0.88(0.79-0.99)^{*}$ & & $0.89(0.80-1.08)$ \\
\hline$\geq 25$ & & $0.70(0.58-0.85)^{*}$ & & $0.71(0.59-0.86)^{*}$ \\
\hline \multicolumn{5}{|c|}{ Health care access } \\
\hline \multicolumn{5}{|c|}{ Covered by health insurance } \\
\hline No & & 1.00 & & 1.00 \\
\hline Yes & & $1.08(0.82-1.42)$ & & $1.12(0.85-1.48)$ \\
\hline \multicolumn{5}{|c|}{ Visiting health facility in the last 12} \\
\hline No & & 1.00 & & 1.00 \\
\hline Yes & & $0.95(0.6-1.04)$ & & $0.96(0.87-1.06)$ \\
\hline \multicolumn{5}{|c|}{ Community-level characteristics } \\
\hline \multicolumn{5}{|c|}{ Place of residence } \\
\hline Urban & & & 1.00 & 1.00 \\
\hline Rural & & & $1.47(0.98-2.19)$ & $1.10(0.82-1.46)$ \\
\hline \multicolumn{5}{|c|}{$\%$ of women with high decision-making autonomy } \\
\hline Low & & & 1.00 & 1.00 \\
\hline Medium & & & $0.36(0.25-0.51)^{*}$ & $0.54(0.40-0.73)^{*}$ \\
\hline High & & & $0.26(0.18-0.38)^{*}$ & $0.50(0.47-0.69)^{*}$ \\
\hline \multicolumn{5}{|c|}{$\%$ women with higher education } \\
\hline Low & & & 1.00 & 1.00 \\
\hline Medium & & & $0.72(0.53-0.97)^{*}$ & $0.69(0.54-1.09)$ \\
\hline High & & & $0.93(0.65-1.32)$ & $0.89(0.66-1.20)$ \\
\hline \multicolumn{5}{|c|}{$\%$ of women with non-poor wealth index } \\
\hline Low & & & 1.00 & 1.00 \\
\hline Medium & & & $0.70(0.49-1.01)$ & $0.76(0.56-1.03)$ \\
\hline High & & & $0.66(0.41-0.85)^{*}$ & $0.78(0.52-0.97)^{*}$ \\
\hline
\end{tabular}


Table 3 Multilevel analyses of factors associated with anemia, among married women in Ethiopia (Continued)

\begin{tabular}{cllll}
\hline Variables & \multicolumn{1}{c}{ Model I } & $\begin{array}{l}\text { Model 2 } \\
\text { AOR(95\%Cl) }\end{array}$ & Model 3 AOR(95\%Cl) & Model 4 AOR(95\%Cl) \\
\hline ICC & \multicolumn{1}{c}{$0.46^{*}$} & $0.29^{*}$ & $0.39^{*}$ & $0.27^{*}$ \\
PCV (\%) & Ref. & 50.7 & 23.2 & 56.4 \\
Model fit statistics & & & & $13,484.7$ \\
BIC & $14,845.3$ & $13,538.1$ & $14,722.2$ & \\
\hline
\end{tabular}

AOR Adjusted odds ratio, $C l$ confidence interval, ICC intraclass correlation coefficient, $B I C$ Bayesian information criterion, ${ }^{*}$ : Significant at $P$-value $<0.05$. Note: Boldface indicates the statistical significance values

[60]. Based on our findings, we suggest that anemia prevention interventions in Ethiopia must focus on encouraging secure nutritional exercises to keep a healthy body mass index and endorse iron supplements to confirm ideal nourishment among women, because overweight/obesity is an emerging problem in developing countries, including Ethiopia.

\section{Limitations}

This research has some limitations. First, due to the nature of a cross-sectional study design, we were unable to establish cause-and-effect relationships among explanatory and outcome variables. Second, due to the fact this study is based on secondary records analysis, we are not able to account for all confounding factors. Third, the use of administratively defined boundaries has possible to introduce misclassification for improper administrative classifications. Fourth as most previous empirical studies, our study not completely integrated theory into our conceptualizations and selection of factors. As a result, some measurements might be inaccurate or biased. In spite of these limitations, this study employed a large sample of married women in Ethiopia; consequently our findings may be representative of Ethiopian married women.

\section{Conclusion}

This study underscores the importance of individual and group-level factors in assessing women's decisionmaking autonomy and anemia prevalence. Group-level women's decision-making autonomy and wealth index at the group-level were important factors associated with the prevalence of anemia among married women in Ethiopia. Women's, age, religion, number of children ever born, use of contraceptive, nutritional status, employment and pregnancy status also important factors linked to anemia. The negative relationship between group-level women's decision-making autonomy with anemia may suggest a requirement for implementing programs and policies to increase women's decisionmaking autonomy in Ethiopia. The government can focus on community awareness regarding women's rights related to their health. Interventions to increase the economic status of women at the community level should be also implemented.

\author{
Abbreviations \\ AOR: Adjusted Odd Ratio; BIC: Bayesian Information Criterion; BMI: Body mass \\ index; Cl: Confidence Interval; CSA: Central Statistical Agency; \\ EAs: Enumeration Areas; EDHS: Ethiopia Demographic Health Survey; \\ ICC: Intraclass Correlation Coefficient; SAS: Statistical Analysis Software; \\ WHO: World Health Organization
}

\section{Supplementary Information}

The online version contains supplementary material available at https://doi. org/10.1186/s12889-021-11538-6.

\section{Additional file 1: Table 1. Multicollinearity examination.}

\section{Acknowledgments}

We thank MEASURE DHS for granting us permission to analyze the EDHS data set.

Authors' contributions

FNT designed the study, applied for data access, analyzed the data and drafted the manuscript. DTA, MWT and HA revised the draft. All authors read and approved the final manuscript.

Funding

There was no funding for this study.

Availability of data and materials

The datasets used in this study can be found at: http://dhsprogram.com/ data/Access-Instructions.cfm

\section{Declarations}

Ethics approval and consent to participate

The Institutional Review Board of ICF International, the Ministry of Innovation and Technology, and the Federal Democratic Republic of Ethiopia all reviewed and approved the survey protocol, which included biomarker collection. The authors obtained permission to use the data from the DHS program website through written consent:https://dhsprogram.com/data/ dataset/Ethiopia_Standard-DHS_2016.cfm?flag=0

Consent for publication

Not applicable.

Competing interests

The authors declare that they do not have any competing interests.

Received: 2 September 2020 Accepted: 22 July 2021

Published online: 03 August 2021

References

1. Hemoglobin concentrations for the diagnosis of anemia and assessment of severity. World Health Organization, 2011. Accessed August 2020 https:// www.who.int/vmnis/indicators/haemoglobin.pdf

2. Kassebaum NJ. The global burden of anemia. J Hematol Oncol. 2016;30(2): 247-308. 
3. World Health Statistics: Prevalence of anemia among women of reproductive age Assessed in March 2021 https://data.worldbank.org/indica tor/SH.ANM.ALLW.ZS

4. Stevens GA, Finucane MM, De-Regil LM, Paciorek CJ, Flaxman SR, Branca F, et al. Global, regional, and national trends in hemoglobin concentration and prevalence of total and severe anemia in children and pregnant and nonpregnant women for 1995-2011: a systematic analysis of populationrepresentative data. Lancet Glob Health. 2013;1(1):e16-25. https://doi.org/1 0.1016/S2214-109X(13)70001-9.

5. Ethiopia demographic and health survey, 2016. Accessed August 2020 https://dhsprogram.com/pubs/pdf/FR328/FR328.pdf

6. Adamu AL, Crampin A, Kayuni N, Amberbir A, Koole O, Phiri A, et al. Prevalence and risk factors for anemia severity and type in Malawian men and women: urban and rural differences. Popul Health Metrics. 2017;15(1): 12. https://doi.org/10.1186/s12963-017-0128-2.

7. Pasricha S-R, Drakesmith H, Black J, Hipgrave D, Biggs B-A. Control of iron deficiency anemia in low-and middle-income countries. Blood. 2013;121(14) 2607-17. https://doi.org/10.1182/blood-2012-09-453522.

8. Lee J-O, Lee JH, Ahn S, Kim JW, Chang H, Kim YJ, et al. Prevalence and risk factors for iron deficiency anemia in the Korean population: results of the fifth Korea National Health and nutrition examination survey. J Korean Med Sci. 2014;29(2):224-9. https://doi.org/10.3346/jkms.2014.29.2.224.

9. Harding KL, Aguayo VM, Namirembe G, Webb P. Determinants of anemia among women and children in Nepal and Pakistan: an analysis of recent national survey data. Maternal Child Nutr. 2018;14:e12478.

10. Mistry R, Galal O, Lu M. Women's autonomy and pregnancy care in rural India: a contextual analysis. Soc Sci Med. 2009;69(6):926-33. https://doi.org/1 0.1016/j.socscimed.2009.07.008

11. Osamor PE, Grady C. Women's autonomy in health care decision-making in developing countries: a synthesis of the literature. Int J Womens Health. 2016:8:191.

12. Green SH, Wang C, Ballakrishnen SS, Brueckner H, Bearman P. Patterned remittances enhance women's health-related autonomy. SSM Popul Health. 2019:9:100370. https://doi.org/10.1016/j.ssmph.2019.100370.

13. Peterman A, Schwab B, Roy S, Hidrobo M, Gilligan DO. Measuring Women's Decisionmaking: indicator choice and survey design experiments from cash and food transfer evaluations in Ecuador, Uganda, and Yemen. World Dev. 2021;141:105387. https://doi.org/10.1016/j.worlddev.2020.105387.

14. Seymour G, Peterman A. Context and measurement: an analysis of the relationship between intrahousehold decision making and autonomy. World Dev. 2018;111:97-112. https://doi.org/10.1016/j.worlddev.2018.06.027.

15. Dancer D, Rammohan A. Maternal autonomy and child nutrition. Indian Growth Dev Rev. 2009:2(1):1753-8254.

16. Woldemicael G, Tenkorang EY. Women's autonomy and maternal healthseeking behavior in Ethiopia. Matern Child Health J. 2010;14(6):988-98. https://doi.org/10.1007/s10995-009-0535-5

17. Singh K, Haney E, Olorunsaiye C. Maternal autonomy and attitudes towards gender norms: associations with childhood immunization in Nigeria. Matern Child Health J. 2013;17(5):837-41. https://doi.org/10.1007/s10995-012-1060-5.

18. Ebot JO. Place matters community level effects of women's autonomy on Ethiopian children's immunization status. Afr Popul Stud. 2014;28(2):120215. https://doi.org/10.11564/28-0-568.

19. Tiruneh FN, Chuang K-Y, Chuang Y-C. Women's autonomy and maternal healthcare service utilization in Ethiopia. BMC Health Serv Res. 2017;17(1): 718. https://doi.org/10.1186/s12913-017-2670-9.

20. Kravdal $\varnothing$. Child mortality in India: the community-level effect of education. Popul Stud. 2004;58(2):177-92. https://doi.org/10.1080/0032472042000213721.

21. Organization $\mathbf{W H}$. Haemoglobin concentrations for the diagnosis of anaemia and assessment of severity: World Health Organization; 2011.

22. Liyew AM, Teshale AB. Individual and community level factors associated with anemia among lactating mothers in Ethiopia using data from Ethiopian demographic and health survey, 2016; a multilevel analysis. BMC Public Health. 2020;20:1-11. https://doi.org/10.1186/s12889-020-08934-9.

23. Tiruneh FN, Chuang K-Y, Ntenda PAM, Chuang Y-C. Individual-level and community-level determinants of cervical cancer screening among Kenyan women: a multilevel analysis of a Nationwide survey. BMC Womens Health. 2017;17(1):109. https://doi.org/10.1186/s12905-017-0469-9.

24. Tiruneh FN, Chuang K-Y, Ntenda PA, Chuang Y-C. Unwanted pregnancy, pregnancy loss, and other risk factors for intimate partner violence in the Democratic Republic of the Congo. Women Health. 2018:58(9):983-1000. https://doi.org/10.1080/03630242.2017.1377800.
25. Howe LD, Galobardes B, Matijasevich A, Gordon D, Johnston D, Onwujekwe $\mathrm{O}$, et al. Measuring socio-economic position for epidemiological studies in low-and middle-income countries: a methods of measurement in epidemiology paper. Int J Epidemiol. 2012;41(3):871-86. https://doi.org/10.1 093/ije/dys037.

26. Ene M, Leighton EA, Blue GL, Bell BA. Multilevel models for categorical data using SAS ${ }^{\circledast}$ PROC GLIMMIX: the basics. SAS Global Forum. 2015:1-2 Accessed March 2021: https://support.sas.com/resources/papers/ proceedings15/3430-2015.pdf.

27. Gerber W. Addressing the issue of gender in achieving universal health coverage. In: Global Health Impact Medford, MA: Management Sciences for Health; 2013. Accessed Feburary 2021: https://www.msh.org/blog/2013/05/2 8/addressing-the-issue-of-gender-in-achieving-universal-health-coverage.

28. Barker G, Contreras JM, Heilman B, Singh A, Verma R, Nascimento M. Evolving Men. Initial Results from the International Men and Gender Equality Survey (IMAGES): ICRW; 2011. Accessed February 2021: https:// promundoglobal.org/resources/evolving-men-initial-results-from-the-interna tional-men-and-gender-equality-survey-images/?lang=english

29. Mohammed A, Woldeyohannes D, Feleke A, Megabiaw B. Determinants of modern contraceptive utilization among married women of reproductive age group in north Shoa zone, Amhara region, Ethiopia. Reprod Health. 2014;11(1):13. https://doi.org/10.1186/1742-4755-11-13.

30. Jennings EA, Barber JS. The influence of neighbors' family size preference on progression to high parity births in rural Nepal. Stud Fam Plan. 2013; 44(1):67-84. https://doi.org/10.1111/j.1728-4465.2013.00344.x.

31. Janevic T, Sarah PW, Leyla I, Elizabeth BH. Individual and community level socioeconomic inequalities in contraceptive use in 10 newly independent states: a multilevel cross-sectional analysis. Int J Equity Health. 2012;11(1):69. https://doi.org/10.1186/1475-9276-11-69.

32. Abate MG, Tareke AA. Individual and community level associates of contraceptive use in Ethiopia: a multilevel mixed effects analysis. Arch Public Health. 2019;77(1):46. https://doi.org/10.1186/s13690-019-0371-z.

33. Msemo OA, Bygbjerg IC, Møller SL, Nielsen BB, Ødum L, Perslev K, et al. Prevalence and risk factors of preconception anemia: a community based cross sectional study of rural women of reproductive age in northeastern Tanzania. PLoS One. 2018;13(12):e0208413. https://doi.org/10.1371/journal. pone.0208413.

34. Sadeghian M, Fatourechi A, Lesanpezeshki M, Ahmadnezhad E. Prevalence of anemia and correlated factors in the reproductive age women in rural areas of Tabas. J Family Reprod Health. 2013;7(3):139-44.

35. Nankinga O, Aguta D. Determinants of Anemia among women in Uganda: further analysis of the Uganda demographic and health surveys. BMC Public Health. 2019;19(1):1-9.

36. Alemu B. Early marriage in Ethiopia: causes and health consequences. Exchange HIV AIDS Sexuality Gender. 2008;1:4-6.

37. Edmeades J, Lee-Rife SM, Malhotra A. Women and reproductive control: the nexus between abortion and contraceptive use in Madhya Pradesh, India. Stud Fam Plan. 2010;41(2):75-88. https://doi.org/10.1111/j.1728-4465.2010.00228.x.

38. World Health Organization. Intermittent iron and folic acid supplementation in menstruating women: WHO Guidel; 2011. p. 1-30. Accessed June, 2021: https://apps.who.int/iris/bitstream/handle/10665/44649/9789241502023 eng.pdf

39. Desalegn BB, Lambert C, Riedel S, Negese T, Biesalski HK. Ethiopian orthodox fasting and lactating mothers: longitudinal study on dietary pattern and nutritional status in rural Tigray, Ethiopia. Int J Environ Res Public Health. 2018;15(8):1767. https://doi.org/10.3390/ijerph15081767.

40. Sarri $\mathrm{KO}$, Kafatos $\mathrm{AG}$, Higgins $\mathrm{S}$. Is religious fasting related to iron status in Greek orthodox Christians? Br J Nutr. 2005;94(2):198-203. https://doi.org/10.1 079/BJN20051472.

41. Bansal B, Takkar J, Soni N, Agrawal DK, Agarwal S. Comparative study of prevalence of anemia in Muslim and non-Muslim pregnant women of western Rajasthan. Int J Res Health Sci. 2013;1(2):47-52.

42. Lakshmi Manjeera M, Neetha SR. Contraceptive practices among reproductive age group of women in justice KS Hegde medical college hospital, Mangalore. Int J Reprod Contracept Obstet Gynecol. 2013;2(1):3946.

43. Dinant G-J, Gebreyesus SH, Spigt M. Geospatial inequality of Anemia among children in Ethiopia. Research square 2020; research square. Doi: https://doi. org/10.21203/rs.3.rs-54237/v1

44. Najafi-Sharjabad F, Yahya SZS, Rahman HA, Hanafiah M, Manaf RA. Barriers of modern contraceptive practices among Asian women: a mini literature 
review. Global J Health Sci. 2013;5(5):181-92. https://doi.org/10.5539/gjhs. v5n5p181.

45. Osman MO, Nour TY, Bashir HM, Roble AK, Nur AM, Abdilahi AO. Risk factors for Anemia among pregnant women attending the antenatal care unit in selected Jigjiga public health facilities, Somali region, East Ethiopia 2019: unmatched case-control study. J Multidiscip Healthc. 2020;13:769-77. https://doi.org/10.2147/JMDH.S260398.

46. Mekonnen FA, Ambaw YA, Neri GT. Socio-economic determinants of anemia in pregnancy in north Shoa zone, Ethiopia. PLoS One. 2018;13(8): e0202734. https://doi.org/10.1371/journal.pone.0202734.

47. Taruvinga A, Muchenje V, Mushunje A. Determinants of rural household dietary diversity: the case of Amatole and Nyandeni districts, South Africa. Int J Dev Sustain. 2013;2(4):2233-47.

48. Sifakis S, Pharmakides G. Anemia in pregnancy. Ann N Y Acad Sci. 2000; 900(1):125-36.

49. Ciliberto CF, Marx GF, Johnston D. Physiological changes associated with pregnancy. Update Anaesth. 2008;24(2):72-6.

50. Kikafunda JK, Lukwago FB, Turyashemererwa F. Anaemia and associated factors among under-fives and their mothers in Bushenyi district, Western Uganda. Public Health Nutr. 2009;12(12):2302-8. https://doi.org/10.1017/S13 68980009005333.

51. Mawani M, Ali SA, Bano G, Ali SA. Iron deficiency anemia among women of reproductive age, an important public health problem: situation analysis. Reprod Syst Sex Disord Curr Res. 2016;5(3):1.

52. Obse N, Mossie A, Gobena T. Magnitude of anemia and associated risk factors among pregnant women attending antenatal care in Shalla Woreda, west Arsi zone, Oromia region, Ethiopia. Ethiop J Health Sci. 2013;23(2):16573.

53. Naik R, Smith R. Impacts of family planning on nutrition. 2015. Accessed June 2021: https://www.healthpolicyproject.com/pubs/690_FPa ndnutritionFinal.pdf

54. Haile ZT, Teweldeberhan AK, Chertok IR. Association between oral contraceptive use and markers of iron deficiency in a cross-sectional study of Tanzanian women. Int J Gynecol Obstet. 2016;132(1):50-4. https://doi. org/10.1016/.j.jgo.2015.06.040.

55. Sunuwar DR, Singh DR, Chaudhary NK, Pradhan PMS, Rai P, Tiwari K. Prevalence and factors associated with anemia among women of reproductive age in seven south and southeast Asian countries: evidence from nationally representative surveys. PLoS One. 2020;15(8):e0236449. https://doi.org/10.1371/journal.pone.0236449.

56. Al-Eisawi Z, Rababah E. The burden of Anaemia among women in Jordan. Curr Womens Health Rev. 2020;16(3):220-8. https://doi.org/10.2174/1573404 816999200420083638.

57. Gautam S, Min H, Kim H, Jeong H-S. Determining factors for the prevalence of anemia in women of reproductive age in Nepal: Evidence from recent national survey data. PLoS One. 2019;14(6):e0218288 Doi. doi.org/10.1371.

58. Hakizimana D, Nisingizwe MP, Logan J, Wong R. Identifying risk factors of anemia among women of reproductive age in Rwanda-a cross-sectional study using secondary data from the Rwanda demographic and health survey 2014/2015. BMC Public Health. 2019;19(1):1662. https://doi.org/10.11 86/s12889-019-8019-z

59. Hisa K, Haruna M, Hikita N, Sasagawa E, Yonezawa K, Suto M, et al. Prevalence of and factors related to anemia among Japanese adult women: secondary data analysis using health check-up database. Sci Rep. 2019;9(1): $1-8$.

60. Ghose B, Yaya S, Tang S. Anemia status in relation to body mass index among women of childbearing age in Bangladesh. Asia Pac J Public Health. 2016;28(7):611-9. https://doi.org/10.1177/1010539516660374.

\section{Publisher's Note}

Springer Nature remains neutral with regard to jurisdictional claims in published maps and institutional affiliations.

Ready to submit your research? Choose BMC and benefit from:

- fast, convenient online submission

- thorough peer review by experienced researchers in your field

- rapid publication on acceptance

- support for research data, including large and complex data types

- gold Open Access which fosters wider collaboration and increased citations

- maximum visibility for your research: over $100 \mathrm{M}$ website views per year

At BMC, research is always in progress.

Learn more biomedcentral.com/submissions 